\title{
Commentary
}

\section{Synthesis of the symposium and conclusions}

\author{
Bernard CHEVASSUS-AU-LOUIS*
}

Muséum National d'Histoire Naturelle, rue Cuvier, 75005, Paris, France

\begin{abstract}
Reflexive biology", using the ambiguities of the term, is altogether a biology that plays with the mirrors of the different levels of organisation, which, endlessly, go from one place to another, organisms in their real environment to the genome via cells in vitro and others, but which is also reflexive because at any moment biology reflects the finalities and the worry of what it should serve.
\end{abstract}

comparative biology / evolutive biology / systemic biology / integrative biology

A summary and conclusion, those are big words. What I would only like tonight, is to gather several flowers from these past few days in order to make a bouquet of tribute, and then to allow you, like when we rewind a film, to rapidly relive these moments that we have spent together and that, I believe, will remain in our memories.

In a gathering made up of prestigious physiologists, you have entrusted a nonphysiologist, a geneticist, with the task of summarising these days. And I read yesterday a text written by Charles Thibault: "our relationships with geneticists have always been difficult to establish, since geneticists have privileged population genetics and have always had a difficult time in integrating knowledge of physiology, and notably - he added - to exploit the non-apparent physiological possibilities of the animal". So, Charles Thibault was opposed to the brutal practice of genetic selection. He tried to find what works the best, with the attitude of a physiologist who was going to permit each animal to express an unrecognised potential. Retain this idea; it will come up again later.

This is maybe the reason why I accepted, or at least it is the first reason why I accepted, because I am persuaded that a large part of what makes up the richness of INRA, what the institute has succeeded in doing and what it will succeed in doing tomorrow is the dialectic incarnated by two exemplary persons, Jacques Poly and Charles Thibault, who in their diversity, each with his own personality and his own approach, contributed to making the INRA of today and that of tomorrow. I was surprised during these days that, for example, Ronald Hunter, made an allusion to the fact that physiologists should integrate the population dimension and, on a lighter tone, I was surprised that Louis-Marie Houdebine tried to present to us, if the method had not betrayed him, possibilities of new convergences between physiology and genetics. I believe that if Charles Thibault and Jacques Poly are together somewhere, they must have laughed up a

\footnotetext{
* Corresponding author: bcal@cimrs1.mnhn.fr
} 
storm about this technical accident that will delay the synthesis to which we aspire.

The second surprising thing. You have entrusted a representative of lower vertebrates, which, earlier an orator did not even seem to consider as animals since he said "animals and lower vertebrates", you have thus entrusted a representative of lower vertebrates to speak of these prestigious animals including mammals and men. You know that this notion of "lower" vertebrates is an old translation of the middle-aged scale of beings. It is surprising to note that after five centuries, one continues to consider that, starting with mammals, one goes down little by little towards the lower vertebrates or, even more appalling, towards the invertebrates, with the privative prefix that indicates everything that is missing in them!

This was the second reason I accepted. Indeed, one must admit that if we exist as a community of ichthyologists, it is largely due to Charles Thibault. We owe him this a first time since, when he was one of the 12 wise men of the DGRST (General Delegation of Scientific and Technical Research) of the 1960s, he insisted on the fact that the research on water and forests be linked to INRA, and it is this that allowed, maybe, for us to begin to exist. But then, it is he who, at Jouy-en-Josas, hired a certain number of people to work on fish. Here, I wish to say that he did this with the support and complicity of a certain number of people that are present here, that I have the pleasure to acknowledge: Raymond Février, Gilbert Jolivet and Pierre Mauléon who was with us on Thursday. Lastly, he saved the fish a third time when Jacques Poly decided to send this small group that had been constituted at Jouy to Saint-Pée-sur-Nivelle (or more exactly, he said to us, "at Saint-Péesur-Nivelle or in hell", which at that period did not seem to us to be much of a difference!). He continued to welcome us at Jouy while waiting for the storm to pass. That was, and he wrote somewhere else in his memoirs - there is statutory limitation now - maybe one of the rare cases when he did not agree with Raymond Février, and so you see that we owe him collective gratitude, that encouraged me to speak to you tonight.

My third and last reason, it that I owe him personal gratitude, because I consider that he pronounced one of three maxims that guided me during my career, which, I hope is still far from being over. Let me cite them. The first I owe to Hubert Curien. This maxim states: "An unhappy scientist is a bad scientist." He insisted on the fact that if in daily research we are not happy, one should then go and do something else. The second maxim, I owe to Pierre Douzon that said: "In research, there are people that talk about it and there are people who do it." The contents of this maxim refrain me from making any comment. The third maxim is that of Charles Thibault, that said to me: "You will do a lot of things in your life, but you should be capable at any moment of putting your white coat back on tomorrow morning." I can say that the third maxim has been useful to me many times.

So here are the reasons why I am talking to you today and meeting the challenge, let me admit that I took some courses in physiology and that, when listening to you during these days, I have had the impression of listening to something like a long-forgotten mother tongue, for which the words again gain meaning as we listen to the speeches.

I would like, if you don't mind, to organise this synthesis around two current affairs: that of the researcher and that of the biologist. Charles Thibault was a man turned towards the future, which doesn't mean that he was never interested in the past. You know that he always encouraged researchers to consult old works, to read old publications, but he did this, I would say, like a tree that feeds deep into the earth in order to move more efficiently towards the sky, that is to say that he had the conviction that the knowledge of the past was a better way to project oneself into the future. It is therefore for this reason that I have tried to treat what seemed to me current subjects, through 
his life as a scientist and his occupation as a biologist.

Current affairs of the scientist. I would like to develop three points that we have evoked. The first is the question of the diversity of professions that he had exercised. He was a scientist, which is useless in developing, but he was also excellent at spreading knowledge. He began as a teacher, he was a university professor but, and as Jean Cohen said, he was very present in gynaecology congresses, in order to bring to medical doctors science as it was developing. Michel Thibier also said, he attended symposiums for inseminators, either at Rambouillet or at UNCEIA, and so he was preoccupied by making current, updated science available to those who would really need it. I will not speak here of his other functions, but the general reflection that this inspires in me, is today the question of whether we need professors-scientists (and, in this case, they would have to work $196 \mathrm{~h}$ and we would practically need a decree so that they could only work $190 \mathrm{~h}$ ). And then, we question researchers in the EPST (Public Establishment of a Scientific and Technological Nature) that don't have any functions as teachers; on the engineers of the EPST, that one wonders whether they are or are not researchers; on the researchers-engineers of the EPIC (Public Establishment of an Industrial and Commercial Nature), that have yet another definition. Still again, didn't he do all of this and shouldn't we inquire on a more flexible status that would permit the expression of ones different talents throughout his or her career?

The second current point on which I would like to talk is the notion of excellence. You know that today, especially in a specific newspaper that is edited in the evening, a notion is being developed that I call of "Darwinian" excellence. The excellence would be a process by which we would sort out excellent people, of course, or tending towards excellence, which presents one difficulty. I will read you the passage, "This elitist vision is essential and cannot be ignored. The management of excellence, which implies choices and engenders people-that-are-put-aside" which means that the dilemma of this Darwinian vision, is to find how to generate, at each generation, people-that-are-put-aside who notably allow those who are excellent to verify that they are excellent. I would say and it is for this reason that I talked at the beginning of the opposition between geneticists and physiologists - that Charles Thibault maybe had a vision much more "physiological" of excellence, that is that he had the feeling that each person has a vocation of giving the best of him or herself, and that this is not an elitist vision, since he considered that each person would be brought to do this. I remember how I felt before an appointment with him, like all those who visited Charles Thibault. I concentrated myself before, as a soccer player does before a game, knowing that during the minute or the hour or two hours that he would accord to me, I would absolutely do everything possible to be my best. As others, I would leave the visit exhausted but happy, and I believe that you have all lived this experience.

I would like to read the following text that Charles Thibault wrote about excellence. He wrote: "If all experimentations are excellent, research would be a little onerous. But with the errors that research causes and the passions that are born, the bad experiences are always very costly". But he added, and it is here that we see his vision of things: "The risks of errors always decrease with the number of people called in for reflection. In the laboratory, scientists and technicians need to communicate easily and to exchange ideas before beginning an experience. This is a good insurance for the quality of experimentation. Ethics for a good experience should exist". You see that this message of excellence, and I believe that Charles Thibault was also intransigeant on this subject, is for me a vision much more physiological than Darwinian, and which seems much more pertinent to me today. 
A corollary of this vision of excellence is an ideology of failure, that he announces in a text by saying: "What I loved in research, is the stimulation of memory by failure. Failing more than succeeding is something of which one must know how to profit from". Logically, this excellence by failure implies that at one moment we are not excellent, which I invite you to meditate.

The last aspect of this vision of excellence, which was stated during this symposium, is this idea of giving a place to young, of giving a chance to people that are relatively young. I think that Charles Thibault illustrated this throughout his career and was not one of those that believed that giving the title of a tenured researcher to someone a few years before his retirement is the asymptotic vision to which we should lean. Here is excellence.

On the third point of the occupation of a scientist, I would like to come back to what Claude Sureau evoked, that is the ethics of transgression and precaution. Claude Sureau spoke of the vigilance around medical assisted procreation. Yvan Heyman spoke of this again this morning on cloning and transgenesis. And today a certain number of people, notably on the debate of the environmental charter, would like to develop a sophistry or at least a false dilemma, stating that one must choose between precaution or innovation, and that science in particular should choose one of these camps, and of course should be situated in the camp of innovation. I believe that Charles Thibault would not have appreciated this opposition and this challenge, this obligation for science to choose a specific camp. I think that science nourishes and is nourished by the dynamics of innovation as well as the legitimate questions on the consequences of these innovations. If science goes beyond these limits in both domains, science should go beyond these limits by developing these innovations that at a specific moment may appear inappropriate, or at least elaborate the bases for such innovations, but should also perceive before others what could be the unex- pected consequences of these innovations that science is preparing and begin as soon as possible the research necessary that takes into consideration these consequences. I believe that these ethics of transgression and precaution would have been formulated much more delicately by Charles Thibault than by some people that are currently giving their opinion on the subject.

The second part of my summary concerns Charles Thibault, the biologist. You know that when Jean-Baptiste Lamarck in 1802 introduced the term biology, it was not to underline the originality of living beings as compared to the rest of matter - the term botanic or zoology had already been introduced in the XVIth or XVIIth centuries - in order to affirm that he wanted to construct what was called living physics, that is to understand what were the causes implicated through what he observed in biological phenomena, and to go from a descriptive phase to a phase of the understanding of mechanisms. It is this specific sense of the word "biology" that Charles Thibault illustrated.

During this symposium we have observed how Charles Thibaut juggled with virtuosity the in vivo, in vitro and in situ approaches that he described in numerous texts, "in the laboratory when things work well, one must immediately go and see if on the farm that works well there too", and in this domain he had bad experiences as well as good ones. He did not develop in silico approaches, which were not yet relevant, even if some remember the first "computer" machines that he wanted to introduce into his laboratory. I can see that this makes some smile. In any case, it is not under this angle that I would like to organise a reflection, but rather around a certain number of neologisms that today appear in the scenery and that attempt to define the biology of tomorrow, through terms like comparative biology, evolutive biology, systemic biology or integrative biology. Even if Charles Thibault, I believe, did not use these terms, I would like to show how he had already given them some contents and maybe contents much 
richer than what some people currently give them.

Comparative biology. Sometimes one learns much more by going from one species to another, by comparing them, than by trying to meticulously decorticate a species considered as a model. I do not believe that he appreciated this last word. One can state that he was a virtuoso of using living diversity so to understand phenomena. René Ozon gave us an example of the question of the factors that induce maturation and the interest of a comparison of amphibian and mammal models. Bernard Jégou did too, with the idea of creating a databank in order to compare the fundamental mechanisms of gametogenesis. If I have one humble remark to make, I believe, that if he uses the genome of a plant, I would prefer that he not consider the phanerogam, but that he use a plant with active spermatozoa, such as bryophytes or ginkgos, since of course the pollen tube of phanerogams is not ideal for the establishment of homologies.

Bernard Jalabert told us of this idea that Charles Thibault had had: "Things are not progressing in mammals, lets consider fish." You know that today is the day of Saint Joseph, and I would like to consider this craftsman's example in order to see how Charles Thibault treated comparative biology. Indeed, I had the impression that he played with comparative biology as a carpenter that works matter, and he knew how to go from one tool to another to find the answer to his question. What was important to him was how to understand things, and for him comparative biology was indeed using the diversity of models in a very opportunistic and pragmatic way in order to progress towards the answer to his question. This is, possibly, a very attractive definition of comparative biology.

Evolutive biology now. You know that the geneticist Dobzansky is responsible for one of the most radical sentences of biology. He said: "Nothing in biology can be understood without the light of evolution." You know that Charles Thibault began as a student of Grassé, and we are not talking poorly of Grassé by considering that he was a Darwinian sceptic. He was, and I believe Charles Thibault was too, sceptic of a too dogmatic vision of evolution as proposed by Darwinism or neoDarwinism. He had, I believe, a much more subtle vision of what evolution was. Here is one of his texts: "How can living organisms arrive to the same point by different mechanisms? Why do they use the same family of hormones or mediators to execute similar or on the contrary, different functions? It is possible, by comparing species, to study how a specific molecule or hormone, present from the beginning of time, can, by a few limited structural changes, pilot these functions in species as different as worms and mice, or mice and men." Ibelieve that Charles Thibault would be much more comfortable today with the notion of an evolution due to contingent temporal events than to a logic of optimisation that was the result of classical neo-Darwinism. The fact that today we understand a biological phenomenon as being the result of a history, a contingent event that at a specific moment has appeared on the phylogenetic tree, and that we do not try to find a logic of absolute optimisation at each physiological function or at each mechanism that we describe, is a vision for which we have many examples. I am going to describe a few for you here.

Raymond Counis: the loss of the tail of the end of the GnRH receptor probably occurred about 80 million years ago in small mammals that ran around between dinosaurs feet. Was this really adaptive or indeed how did mammals succeed, without using humour, to compensate for this loss of a tail by reactivating their system of regulation? Here is a first interesting makeshift hypothesis.

Yves Combarnous, explained how we could do very different things with the same peptide skeleton by only playing on glycosylation at the terminal end. If this is not a make-shift job then what is it? 
Similarly, we have seen how the placental lactogenic hormone has fixed up a specific receptor, by borrowing two monomers from two different receptors that worked earlier on. The least that we can say, that this is an example of a lack of resources.

Marc Fellous: why is it practically impossible to find the SRY gene in one species or another, even when comparing mammals that are very closely related, whereas, when we look for FOXL2 in different fish, we find that this gene is hyperconserved. In both cases, one speaks of genes involved in sexual differentiation. Why do some genes have high variability and why are others well conserved? We describe the phenomena but we are very far from understanding them.

What I would like to say to conclude this sequence on evolutive biology, is that it is a field in which this understanding of what is universal, of what can be modified, of what cannot be modified, should federate all biologists, whether they work in finalised, fundamental or applicated biology.

Systemic biology. The people that defend this concept introduce the idea that, in complex systems, it is not the understanding of properties of elementary entities but rather the understanding of their interactions in time and space that allow understanding a phenomenon. We have seen some beautiful examples of this approach by students or colleagues of Charles Thibault.

A beautiful example of a bad temporal coupling of phenomena is when we observe that a mouse that expresses a receptor for constitutive LH has a difficulty in realising a lactation because it does not express the receptor at the right moment, it is. There is also a beautiful example of spatio-temporal determinism when Nicole Le Douarin speaks to us of the subtle dialogue of a cell with its environment, as much of the depart of as the arrival, that will indeed condition the cell types that it will lead to in part. Another very nice illustration is when Jean-François Nicolas explained to us similar things in the case of a hair follicle, by showing that the cells go from a pluripotent stage to a stage of progressive differentiation depending on where they are located.

I will only say a few things of what JeanPierre Ozil and Jean-Paul Renard developed this morning, on the dialogue between the genome and its environment, and this could surprise you since it is coming from a geneticist. But I must say that this vision of a genome that is a little bit tossed back and forth in time and space and solicited by diverse signals, intern or extern to the organism, pleases me much more than a vision of the genome on its perched determinism, a vision that would indeed govern the organism as if from high up on a control tower. The genome seems here much more like a database, a library able to be used depending on the circumstances, than as a pre-established programme.

Another example of the systemic approach. After all, the interaction between the mother and her young, analysed by Pascal Poindron, are after all only a succession of spatio-temporal connections, that can succeed or fail and that will determine the future of the young.

What should be done today with the notion of systemic biology? I will limit myself to two perspectives. The first, and Louis-Marie Houdebine gave an example, is to know how to read the images of tomorrow. It has taken man about 250 years to read in a modern way and especially to interpret what was a phenomenon visible to the naked eye, to understand the evolutive relations between species: the appearance of cladistic and phylogenetic methods occurred in 1960 with William Hennig. Today we have begun to be able to read the organisation of a caryotype, or at least when it is in a metaphase-like stage, but with LouisMarie Houdebine we have found that surprises could be hidden when we look at the interphase stage. We see new images come, images in a broad sense, that are profiles of the expression of thousands of genes with the same principal components that we treat with derived images, like principal component 
analysis, and so the question of knowing how we are going to learn to read and understand these new images constitutes a real challenge. I hope that it won't take us 250 years to meet this challenge.

The second perspective, and I believe that Michel Thibier spoke of this - applying systemic biology to innovation, is that innovation in a socio-economic system is a disruption that we introduce into the system. It is important to learn how to perceive and to anticipate the consequences, by accepting that an innovation perceived by a laboratory as something good can be revealed as having negative consequences once it is introduced into the system.

My last term, and I am almost finished, is that of integrative biology. For some, integrative biology is integrative in the sense that one begins with lower levels of organisation - I wonder more and more about the pertinence of the notion of organisation levels - and one tries from there to understand the properties of the organisation levels that are above them. I believe that Charles Thibault had a much more complex vision of integrative biology not limited to this ascending vision of integrative biology. We could use a mathematical approach: you know that when one integrates a function, one always ends up with an uncertain term that is a constant of inte- gration, and that one can only determine the value of this constant of integration only by setting it on a real value. By keeping this mathematical image, I indeed believe that Charles Thibault had a much more dialectic and back-and-forth vision of what are real, tangible situations and all levels of organisation in which he could try to understand things.

To conclude, when listening to Marion Guillou explain the vision of what she read of integrative biology according to Charles Thibault, I said to myself that after all, in the neologism fair, why not introduce a new one. So, I turned towards Emmanuel Jolivet, who is a mathematician as you know; he suggested a term that I am now submitting to you. It is the notion of "reflexive biology". Reflexive biology, using the ambiguities of the term, is altogether a biology that plays with the mirrors of the different levels of organisation, which, endlessly, go from one place to another, organisms in their real environment to the genome via cells in vitro and others, but which is also reflexive because at any moment biology reflects the finalities and the worry of what it should serve.

If you don't mind, during one evening, I am presenting this neologism to you to try to translate how I see the biology of today, that of Charles Thibault. 